\title{
Scope of management of emergencies in palliative care
}

\author{
Amrallah A. Mohammed ${ }^{1,2}$ \\ ${ }^{1}$ Oncology Center, King Abdullah Medical City-Holy Capital, Saudi Arabia \\ ${ }^{2}$ Medical Oncology department, Faculty of Medicine, Zagazig University, Egypt
}

Abstract: Patients receiving palliative care may deteriorate suddenly due to their illness or another acute medical or surgical problem. Management
options depend on life expectancy, level of intervention needed, and an assessment of risks, benefits, side effects and likely outcome.
Symptom control and supportive care may be the most appropriate management if the patient is dying. Treatment options are to be
discussed with the patient and family; if possible, discussion and documentation of the patient's wishes should be made in advance
including those about resuscitation, hospital admission and transfer to an intensive care unit.
Keywords: Palliative care - Emergencies - Terminal cancer patients
(C) De Gruyter Open

\section{Introduction}

The World Health Organization defines palliative care as "care which improves the quality of life of patients and families who face life-threatening illness, by providing pain and symptom relief, spiritual and psychosocial support from diagnosis to the end-of-life and bereavement" (1). The focus of palliative care is broad and includes several aspects of emergency practice already in place including symptom management, pain management, and discussion of critical decisions with families and loved ones.

In most medical specialties, an emergency is a situation that poses an immediate risk to health, life, property or environment (2). Most emergencies require urgent intervention to prevent a worsening of the situation. In palliative care where death is an expected outcome, emergencies encompass not only situations that are imminently life threatening, but also those that could result in impaired quality of life for the remainder of the patient's life or for the family and prolongation of life is not usually a realistic aim.

\footnotetext{
*E-mail: amrallaabdelmoneem@yahoo.com
}

\section{Assessment}

The concept of rapid assessment, evaluation and management of symptoms due to malignancy is generally accepted. Inherent in this concept is rapid reversal of what is reversible. Some acute events in malignancy have to be treated as an emergency if a favourable outcome is to be achieved. As in any emergency, the assessment must be as prompt and complete as possible. While unnecessary hospital admission may cause distress for the patient and carers, missed emergency treatment of reversible symptomatology can be disastrous.

In patients with advanced malignancy during the evaluation, factors to be considered include: patient, disease or treatment factors (Figure 1).

Regarding diagnostic tests and investigations, the palliative care physician should only investigate if the plan is to offer treatment to patients. If the presenting condition is perceived as a pre-terminal event, palliative care is much more appropriate. 


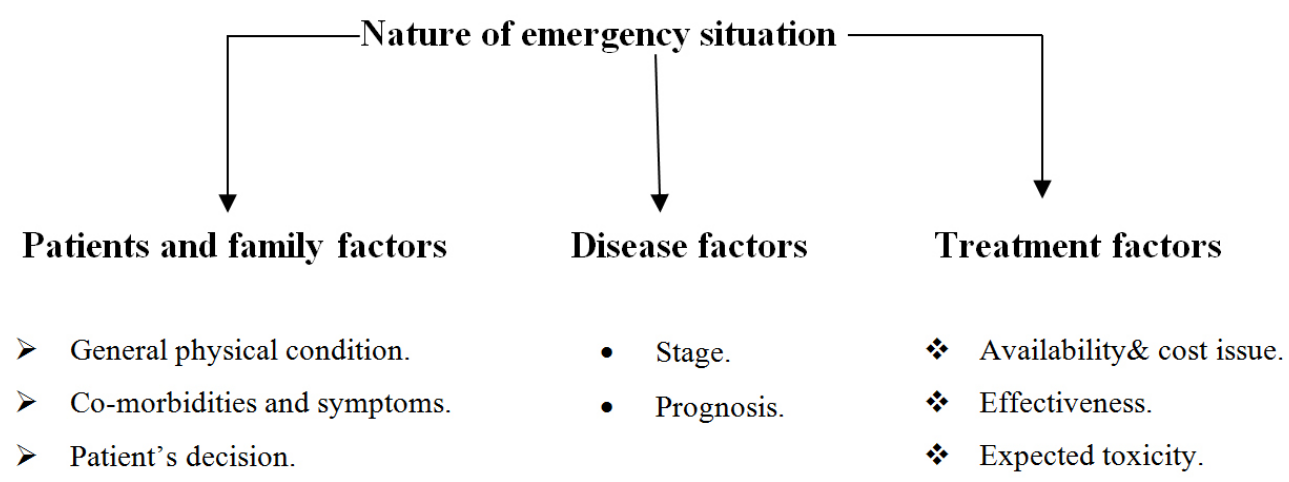

Figure 1. Factors affecting on emergency management.

\section{General rules of management}

Before describing the management of patients presenting with a palliative care emergency, it is vital to consider how professionals should approach care. Patients must be at the centre of any treatment decision, and so communication with the patient, family and friends is paramount. Adherence to a patient-centred approach also fulfils recent recommendations (3). The patient's wishes, which may be influenced by the extent of disease, perceived quality of life and prognosis, must be taken into account when planning treatment. Patients may choose pure palliation of symptoms, declining more acute interventions. Conversely, they may be desperate to accept any treatment in the hope of living longer.

\section{Things we do not want to miss!}

The most common emergencies in palliative care are:

1. Hypercalcaemia

2. Spinal cord compression (SCC)

3. Superior vena cava obstruction (SVCO)

4. Dyspnoea

5. Seizures

6. Haemorrhage

7. Psychiatric emergencies

8. Acute anxiety and delirium

9. Hypoglycaemia

10. Increased intracranial pressure

11. Cardiac tamponade

12. Drug toxicity/side effects.

\section{Hypercalcaemia}

\section{Introduction}

Hypercalcaemia is the presence of abnormally high levels of calcium in the blood. The normal range for calcium is between 2.10 and $2.55 \mathrm{mmol} / \mathrm{L}$. It occurs in about $20 \%-30 \%$ of patients with malignancy with variable incidence according to malignancy type, breast, lung, genito-urinary and haematological malignancies, but can occur with any. Bone metastases are common but are not always present (4).

\section{Pathophysiology}

Paraneoplastic syndrome is mediated by factors such as tumour secreted parathyroid-related protein, inflammatory action of prostaglandins and local interactions by other by-products of inflammation, interleukin 1 and tumour necrosis factor (5).

\section{Symptoms and signs}

Depending on the rate of rise, generally symptoms are not troublesome until calcium level is over $3.0 \mathrm{mmol} / \mathrm{L}$. Common symptoms include: malaise, thirst, nausea, constipation, polyuria and delirium.

\section{Diagnosis}

It is always wise to ask for corrected serum calcium to be done on any patient being investigated for delirium. The diagnosis is usually made on the corrected serum calcium level. A rise of corrected serum calcium of more than $2.6 \mathrm{mmol} / \mathrm{L}$ is diagnostic (6).

\section{Management}

Clinical judgment is required to decide whether to treat or not. Treatment may not be appropriate in a dying patient at the end of life. Raised serum calcium is of itself not an indication to treat, particularly in the terminal phase where treatment can impose unnecessary burden instead of benefit. If the decision is made by the patient not to have treatment or it is deemed inappropriate to treat, the symptoms should be managed appropriately through the terminal phase of illness.

If a decision is made to treat the hypercalcaemia, follow the steps illustrated in Figure 2. 


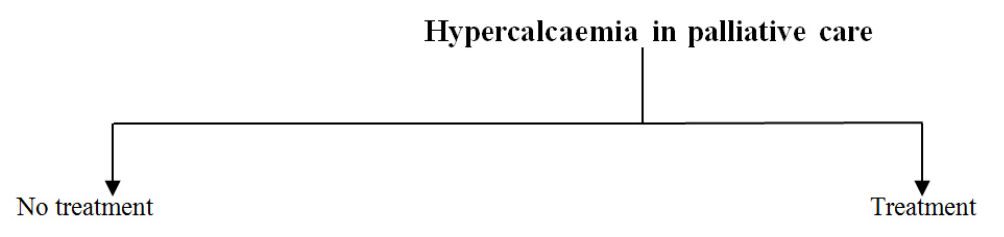

Symptoms control

Reduce agitation,

Treat pain/dyspnea etc...

Support family and friends.

Figure 2.

\section{Spinal Cord Compression}

\section{Introduction}

SCC occurs in up to $5 \%$ of cancer patients and should be considered an emergency as prompt treatment is essential if function is to be maintained. It occurs when the dural sac and its contents are compressed at the level of the cord or cauda equina. Lung, breast and prostate cancer are the commonest causes but it occurs in other cancers. Around $10 \%$ of compressions occur at the cervical level of the spine, $70 \%$ thoracic and $20 \%$ lumbosacral, but it is important to remember that there may be more than one site/level of compression (7).

\section{Pathophysiology}

In $85 \%$ of cases of SCC, the damage results from extension of a vertebral body metastasis into the epidural space. However, other mechanisms do exist, including vertebral collapse, direct spread of tumour through the intervertebral foramen, interruption of the vascular supply and intradural or intramedullary metastases.

\section{Symptoms and signs}

They are variable and so the most important factor in assessing patients is having a high index of suspicion, with the aim being to diagnose the problem when there are symptoms, but before the patient develops progressive neurological signs, as this affords the best chance of remaining ambulatory. The main problem in clinical practice is failure of recognition as neurological symptoms and signs can vary from subtle to gross, and indeed in the earliest stages, the only symptom may be back pain with no neurological findings on examination (8).

Other clinical presentation may be:

a. Stiffness and weakness in lower limbs.

b. Tingling and numbness: Usually rapidly developing from the feet upwards.

c. Urinary symptoms: These are late symptoms with retention and/or incontinence often preceded by a degree of urinary frequency.

d. Peri-anal numbness and lack of anal tone: These are late symptoms.

\section{Diagnosis}

History and neurological examination:

- Sensory examination: the presence of sensory loss and brisk or absent reflexes.

- Motor examination: the presence of motor weakness.

\section{Investigation}

Magnetic resonance imaging (MRI) is the investigation of choice as it can show the whole spine and is noninvasive (computed tomography (CT)). Myelography may still occasionally be required, e.g., if the patient has a pacemaker. 


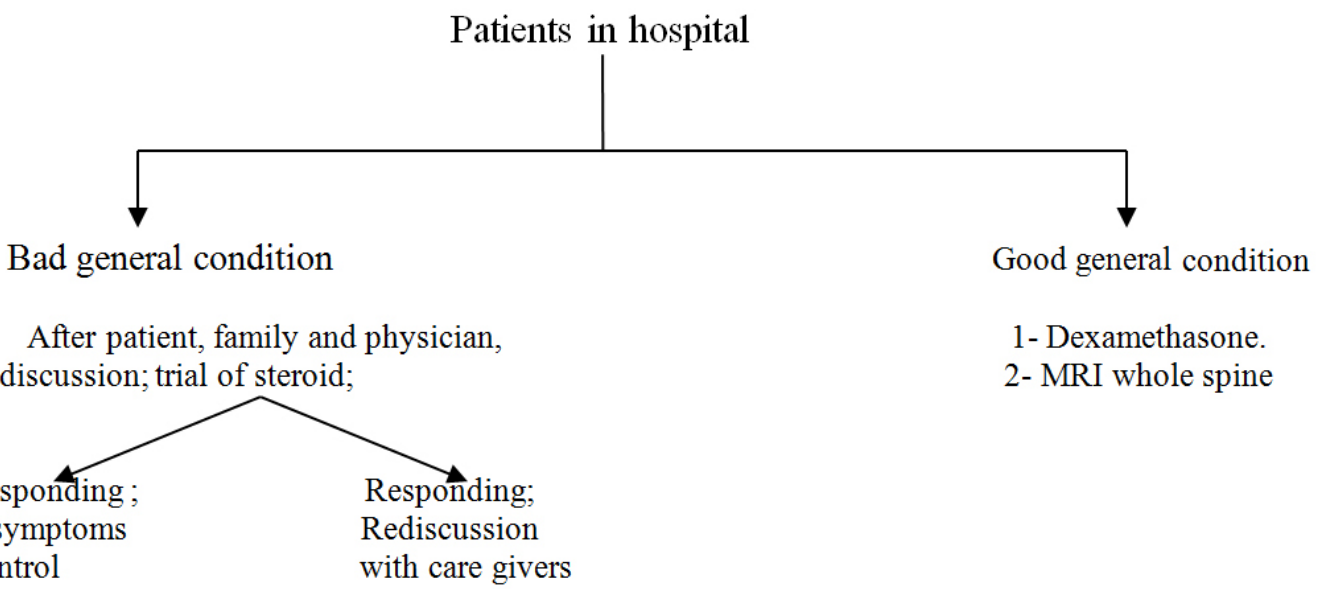

Figure 3.

\section{Management}

Every case of potential SCC irrespective of patient status is best discussed in interdisciplinary approach involving radiologists, oncologists, neurosurgeons and allied health.

\section{Patients in hospital}

When the suspicion of SCC is high, the following management plan should be implemented (Figure 3):

- $16 \mathrm{mg}$ daily of dexamethasone can be given orally, subcutaneously or intravenously if necessary.

- MRI of the whole spine is the investigation of choice and is needed urgently.

- If the patient is very unwell, in the end stages of the illness, the decision of complete investigation and treatment should be carefully considered; it may be more appropriate to give a trial of steroids in hospital and if the patient responds to this treatment, MRI +/other treatments can be reconsidered.

- Discussion with the specialist palliative care team may be useful at this stage (9).

\section{Patients in the community}

When patients are at home and the possibility of SCC is raised, the general practitioner should be contacted in the first instance and asked to assess the situation medically.

a. If SCC is the likely diagnosis, the patient should ideally be referred directly to his or her oncologist at oncology centre for investigation and management.

b. If it is not possible to admit directly to oncology centre, the patient may be admitted to hospital for treatment with steroids and MRI and then transferred as appropriate.
There may be occasional patients in whom admission to the hospice would be appropriate (e.g., end-stage disease, not fit for radiotherapy) but these should be discussed with the hospice medical staff on an individual basis (10). Unfortunately, it is thought that around $75 \%$ of patients with SCC already have significant leg weakness by the time they present to an oncology unit. These facts underline the need for vigilance so that early diagnosis becomes the norm rather than the exception (11).

\section{Superior vena cava obstruction}

\section{Introduction}

SVCO is a condition where the return of blood from the upper body to the heart is impeded resulting in severe upper body congestion; this may be acute or gradual. It often occurs as extrinsic pressure from tumours in the mediastinum. Invasion by intra-luminal thrombus or direct invasions of the vessel wall are less common causes. Lung, lymphoma and metastatic breast cancer are considered the most common causes $(12,13)$.

Benign causes (now rare) occur including goitre, aortic aneurysms, thrombotic syndromes and the use of intravascular devices (14).

\section{Symptoms and signs}

SVCO should be considered if there is:

a. Oedema of face or arms/hands

b. Distended neck or arm veins

c. Headaches (worse on stooping)

d. Dusky colour to skin in chest arms and face

e. Dyspnoea

f. Suffused injected conjunctivae (15). 


\section{Diagnosis and investigation}

Generally in the setting of palliative care, the diagnosis is known. Confirmation of diagnosis is generally done by CT scan and by imaging guided needle biopsy.

\section{Management}

If a patient is too unwell, the focus of care is symptom control. Immediate relief of symptoms such as dyspnoea and anxiety through pharmacological, practical and psychological methods is necessary. Opioids and possibly benzodiazepines are indicated.

\section{Treatment options}

a. Initiation of high dose steroids - $16 \mathrm{mg}$ per day of dexamethasone initially for 5 days and then stopping if not effective or gradually tailing off if effective or as other treatments take effect.

b. Stenting of the SVC may be considered.

c. Radiotherapy may be also considered for radiosensitive tumours (16).

\section{Dyspnoea}

\section{Introduction}

The clinical definition of dyspnoea is an uncomfortable awareness of one's breathing effort. It is a normal symptom of heavy exertion but becomes pathological if it occurs in unexpected situations (17). It occurs in $29 \%$ $90 \%$ of terminally ill patients (18); causes of dyspnoea are diverse but can be related to existing disease, acute superadded illness, cancer-related complications, effects of therapy and miscellaneous causes (Table 1).

\section{Symptoms and signs}

Patients often describe dyspnoea as chest tightness, a feeling of not getting enough air, or a feeling of smothering or suffocation (19).

\section{Diagnosis and investigation}

Diagnostic investigations should be appropriate to disease stage and patient status. Simple tests such as a blood cell count, chest radiography and pulse oximetry may be enough. More complex diagnostics should be avoided in patients at a very advanced stage of disease.

The assessment of dyspnoea in palliative care includes a thorough history and physical examination to try to identify the underlying cause. The impact of dyspnoea on physical function should also be explored (20).

\section{Management}

The management of dyspnoea should address underlying causes while recognising and considering life expectancy, the invasiveness and complications related to therapeutic approaches, and patient and family preferences for treatment and comfort.

Simple causes of breathlessness, such as fluid overload, pain or anxiety, need to be considered and addressed. Effective interventions include diuretics for congestive heart failure, bronchodilators for Chronic obstructive pulmonary disease (COPD), aspirations for pleural or pericardiac effusion, antibiotics for pneumonia, and radiotherapy for obstructing lesions, depending upon patient position on the dying trajectory (21).

Pharmacological palliation of dyspnoea involves opioids, corticosteroids and benzodiazepines.

Opioids are the drugs of choice in dyspnoea in terminal cancer patients because they decrease the perception of breathlessness, decrease response to hypoxia and hypercapnia, and reduce oxygen consumption at rest and during exercise. Therapy should be initiated with oral or sublingual preparations, but as the patient's ability to swallow declines, rectal, intravenous and subcutaneous. Nebulised opioids have been reported to be effective by several authors in managing terminal dyspnoea, but most studies have been anecdotal, and results from available randomised trials are equivocal (22). The use of other nebulised agents, such as furosemide, has also been reported (23) (Table 2).

In tolerant patients, morphine doses may be increased by $50 \%$ to address increasing shortness of breath and titrated by $30 \%-50 \%$ daily or more frequently until respiratory comfort. The starting doses may need to be reduced for the elderly and opioid naive patient- the rule is 'start low and go slow.'

Corticosteroids can be given for their antiinflammatory activity and can be effective for dyspnoea associated with airway obstruction, lymphangitis carcinomatosa, SVCO, COPD and radiation pneumonitis. Long-term side effects are rare in terminal patients. Common drugs and dosages include dexamethasone (4-8 mg/d orally or intravenously), prednisone (20-60 $\mathrm{mg} / \mathrm{d}$ orally) and methylprednisolone (48-128 mg orally or intravenously) (24).

Benzodiazepines are helpful in treating anxiety as a cause of dyspnoea and in providing sedation when required to treat refractory symptoms in the final days of life (Table 5).

Antipsychotics such as chlorpromazine have been used in dyspnoea not responsive to opioids or benzodiazepines. Dosage begins at $12.5 \mathrm{mg}$ intravenously or $25 \mathrm{mg}$ rectally every $4-6$ hours (25). 
General non-pharmacological measures for controlling dyspnoea should be considered. Atherapeutic trial of oxygen may be beneficial for patients with hypoxemia (26). Other measures include positioning the patient in a more upright fashion, improving air circulation by use of a fan or open window, and reassurance and control of anxiety in the patient and family. Families could be taught relaxation techniques to use with their loved ones. Spiritual support and companionship can also reduce anxiety leading to dyspnoea.

\section{Seizures}

Seizures (generalised or partial) occur in 10\%-15\% of palliative care patients most often due to primary or secondary brain tumours, cerebrovascular

Table 1. Common causes of dyspnea.

\begin{tabular}{|c|c|}
\hline Existing disease & Examples \\
\hline $\begin{array}{l}\text { A. ardiac. } \\
\text { B. Pulmonary. }\end{array}$ & $\begin{array}{l}\text { Congestive heart failure. } \\
\text { - } \quad \text { COPD }^{*} \\
\text { - } \quad \text { Asthma }\end{array}$ \\
\hline $\begin{array}{l}\text { Acute super added } \\
\text { illness }\end{array}$ & $\begin{array}{ll}\text { - } & \text { Atelectasis } \\
\text { - } & \text { Pneumonia } \\
\text { - } & \text { Pulmonary embolus }\end{array}$ \\
\hline Cancer-related & $\begin{array}{ll}\text { - } & \text { Bronchial obstruction } \\
\text { - } & \text { Pleural effusion } \\
\text { - } & \text { Lymphangitis carcinomatosa } \\
\text { - } & \text { Superior vena cava syndrome } \\
\text { - } & \text { lung tissue with tumor }\end{array}$ \\
\hline Therapy related & $\begin{array}{ll}\text { - } & \text { Radiation fibrosis } \\
\text { - } & \text { Pneumothorax } \\
\text { - } & \text { Cardiomyopathy } \\
\text { - } & \text { Acute dyspnea syndrome }\end{array}$ \\
\hline Psychiatric disorders & - $\quad$ Anxiety, Depression \\
\hline Miscellaneous & $\begin{array}{ll}\text { - } & \text { Metabolic acidosis } \\
\text { - } & \text { Uremia } \\
\text { - } & \text { Tense Ascites }\end{array}$ \\
\hline
\end{tabular}

${ }^{*}$ Chronic Obstructive Pulmonary Disease.

Table 2. Doses and routes of opioids

\begin{tabular}{c|cc}
\hline Opioids & Route & Starting dose \\
\hline $\begin{array}{c}\text { morphine } \\
\text { (opioids naïve) }\end{array}$ & Orally & 5 to $15 \mathrm{mg} \mathrm{q} 2 \mathrm{~h}$ \\
& Intravenous & $\begin{array}{c}2 \text { to } 5 \mathrm{mg} \\
\text { intravenouslyq2h } \\
2 \text { to } 5 \mathrm{mg} \text { q } 5 \text { to } 10 \\
\text { minutes for acute } \\
\text { dyspnea. }\end{array}$ \\
& Nebulized & $\begin{array}{c}5 \text { to } 10 \mathrm{mg} \text { in } 2 \mathrm{~mL} \\
\text { normal saline } \mathrm{q} 4 \mathrm{~h} .\end{array}$ \\
& Nebulized & 1 to 2 mg in $2 \mathrm{~mL}$ normal \\
saline $\mathrm{q} 4 \mathrm{~h}$.
\end{tabular}

disease, epilepsy or biochemical abnormalities (e.g., hyponatraemia, hypercalcaemia, uraemia). The assessment of seizures includes history of previous seizures or at-risk history of epilepsy, previous secondary seizure and known cerebral disease (27).

Other causes of loss of consciousness or abnormal limb/facial movement (e.g., vasovagal episode (faint), postural hypotension, arrhythmia, hypoglycaemia, extrapyramidal side effects from dopamine antagonists, alcohol) should be excluded (28).

\section{Management}

We have three steps of management: acute seizure, persistent seizures and chronic seizure control (Table 3).

Table 3. Management of seizure

\section{Acute seizure management}

1-Put the patient in the recovery position; move any objects that might cause injury.

2- If seizure does not resolve, anticonvulsant medication is needed.

\section{Medications}

a) Diazepam IV in $2 \mathrm{mg}$ bolus doses up to $10 \mathrm{mg}$ or lorazepam $4 \mathrm{mg}$ by slow IV injection are used

b) Diazepam rectal solution 10-30mg given PR or via a stoma

c) Midazolam SC 5mg, repeated after 5 minutes.

d) Buccal midazolam 10mg can be given using the parenteral preparation

\section{Persistent seizures}

1. IV phenytoin is used in hospital settings.

2. Phenobarbital can be given as $100 \mathrm{mg}$ IM bolus dose followed, if needed, by a subcutaneous infusion of phenobarbital 200-400mg over 24 hrs.

\section{Chronic seizure control}

A. Most patients with a structural cause for seizures benefit from treatment.

B. Follow SIGN* guideline recommendations.

i. Partial or secondary generalised seizures; Sodium valproate, carbamazepine or lamotrigine.

ii. Primary generalised seizures; Sodium valproate or lamotrigine.

C. Dying patient unable to take oral medication - antiepileptics have a long half life so additional anticonvulsant treatment may not be needed.

a. Midazolam SC 5mg or diazepam rectal solution $\mathrm{PR}^{\star \star} 10 \mathrm{mg}$, if required

b. Midazolam SC 20-30mg infusion over $24 \mathrm{hrs}$ can be used as maintenance therapy.

*Scottish Intercollegiate Guidelines Network.

**Per Rectum 


\section{Haemorrhage}

Haemorrhage as a result of advanced cancer is highly distressing for the patient, carers and staff. Severe acute haemorrhage as a terminal event is relatively rare. Clinically significant bleeding occurs in 6\%-10\% of patients with advanced cancer. About $3 \%$ of lung cancer patients have terminal massive haemoptysis (30).

\section{Causes}

There are many causes of bleeding including: tumour related, treatment related or coagulapathy (Table 4).

\section{Management}

It is important to plan and anticipate the probability of haemorrhage and have a strategy for dealing with it; also we must know minor self-limiting episodes of bleeding may precede an acute event. If a patient is having a severe acute haemorrhage he/she should not be left alone.

\section{Non-drug}

- Call for help. Ensure carers at home have an emergency contact number.

- Put the patient in the recovery position.

- Apply direct pressure to any bleeding area; dark coloured towels are best.

- If resuscitation is appropriate, admit to hospital and manage according to local protocols for haemorrhage.

Table 4. Common causes of bleeding

\begin{tabular}{|c|c|}
\hline Etiology & Possible mechanisms \\
\hline $\begin{array}{l}\text { Tumor } \\
\text { related }\end{array}$ & $\begin{array}{ll}\text { - } & \text { Head and neck cancers: malignant neck } \\
\text { - } & \text { Lungeration leading to erosion of a major artery. } \\
\text { - } & \text { Gastrointestinal: haematemasis, malaena } \\
\text { - } & \text { Urological: haematuria, clot retention }\end{array}$ \\
\hline $\begin{array}{l}\text { Treatment } \\
\text { related }\end{array}$ & $\begin{array}{l}\text { - } \quad \text { Mucosal damage; NSAIDs and steroids } \\
\text { - } \quad \text { Chemotherapy induced thrombocytopaenia }\end{array}$ \\
\hline $\begin{array}{l}\text { coagulapathy } \\
\text { related }\end{array}$ & $\begin{array}{l}\text { - } \quad \text { Marrow failure. } \\
\text { - } \quad \text { Thrombo-embolic phenomena including DIC.* }\end{array}$ \\
\hline
\end{tabular}

*Dissiminated Intravascular Coagulopathy.
- If the patient has a massive haemorrhage and is clearly dying, support and non-drug interventions are more important until help arrives than trying to give sedative medication as the patient will usually lose consciousness rapidly.

\section{Crisis orders}

When there is an identified risk of prolonged or severe bleeding and death is inevitable, it is wise to have a CRISIS order for sedation readily available to allow the patient to be unaware of the anxiety and distress that the symptoms of rapidly developing shock produce (31).

\section{A. If a patient is opioid-naive:}

- $10 \mathrm{mg}$ of morphine together with a sedative drug Midazolam $10 \mathrm{mg}$ or Clonazepam $1.0 \mathrm{mg}$ will usually be sufficient initially and can be repeated if necessary at $10 \mathrm{~min}$ intervals (until distress is relieved).

\section{B. If the patient is already on opioids:}

- An opioid dose double the usual breakthrough dose together with a sedative drug is appropriate.

\section{Psychiatric emergencies}

When the patients are presenting with extreme anxiety/apprehension, they will usually respond to benzodiazepines and a calming environment. Agitation may require haloperidol $5 \mathrm{mg}$ repeated if necessary to $10 \mathrm{mg}$ maximum subcutaneously as bolus (reduce in the elderly to half dose). Paranoia and/or aggressive behaviour occasionally occur, especially in patients with cerebral disease. Patients are often very fearful and distressed and despite advanced disease show unexpected mobility and strength. The situation is distressing also for family and professional carers (32) (Table 5).

\section{Exceptionally}

To gain control (preventing harm to self or others), haloperidol $10 \mathrm{mg}$ intramuscularly should be administered. (This may require restraint to enable administration of medication.)

Table 5. Benzodiazepines in palliative emergencies.

\begin{tabular}{c|cc}
\hline Drug & Dose & Maximum \\
\hline \hline Lorazepam & 500 ug sublingually/orally & $30 \mathrm{mg}$ hours \\
Midazolam & 24 hours \\
Diazepam & 5mg orally $5 \mathrm{mg} \mathrm{buccal/subcutaneously}$ & $20 \mathrm{mg}$ in 24 hours \\
\hline
\end{tabular}




\section{Conclusion}

Individual assessment is paramount as treatment will be influenced by patient's wishes, extent of disease, quality of life and aims of care. Three items should be covered during the treatment: symptoms treatment, patient and family treatment and if possible problem treatment. Palliative care emergencies usually aim to heal often; to cure sometimes; and to comfort always. When we are facing with emergency, we must evaluate the patient

\section{References}

[1] World Health Organization. Definition of Palliative Care. Accessed August 15, 2011.

[2] UK Government Advice on Definition of an Emergency. Retrieved 2007-05-30.

[3] National Institute for Health and Care Excellence. Improving supportive and palliative care for adults with cancer, 2011.

[4] Sargent JT, Smith OP. Haematological emergencies managing hypercalcaemia in adults and children with haematological disorders. $\mathrm{Br} \mathrm{J}$ Haematol. 2010; 149: 465-477.

[5] Stewart AF. Clinical practice. Hypercalcemia associated with cancer. N Engl J Med. 2005; 352:373-379.

[6] Evenepoel P, Bammens B, Claes K, Kuypers D, Meijers BK, Vanrenterghem Y. Measuring total blood calcium displays a low sensitivity for the diagnosis of hypercalcemia in incident renal transplant recipients. Clin J Am Soc Nephrol. 2010; 5: 2085-2092.

[7] Downing GM. Neurological - Spinal Cord Compression. In: Downing GM, Wainwright W, editors. Medical Care of the Dying. 4th ed. Victoria, B.C. Canada: Victoria Hospice Society Learning Centre for Palliative

Care; 2006. 470-2.

[8] Wrede-Seaman LD. Management of Emergent Conditions in Palliative Care. Primary Care: Clinics in Office Practice. June 2001; 28:317 - 28.

[9] Klimo P, Kestle JRW, Schmidt MH. Treatment of metastatic spinal epidural disease: A review of the literature. Neurosurgery Focus. 2003November; 15:1-9.

[10] Waller A, Caroline NL. Spinal Cord Compression. Handbook of Palliative Care in Cancer. 2nd ed. Boston, MA; 2000. p. 301-8. Waller A, Caroline NL. Spinal Cord Compression. Handbook of Palliative Care in Cancer.

[11] Rice TW, Rodriguez RM, Light RW. The superior vena cava syndrome: Clinical characteristics and status very well as no further treatment is also an option in the final stages of end-stage illness where the patient is too unwell to have extensive treatment or unlikely to live long enough to have any benefits.

Emergency situations seldom arise unexpectedly. It is therefore possible and important to have not only a high index of diagnostic suspicion but also have a plan in place that either prevents them or institutes prompt intervention.

evolving etiology. Medicine. 2006; 85:37-42.

[12] Osawa S, Sakamoto A, Iwasaki H. Superior vena cava syndrome associated with the metastasis of gastric adenocarcinoma to cervical lymph nodes. Dig Dis Sci. 2007; 5 2:3343-5.

[13] Nunnelee JD. Superior vena cava syndrome. J Vasc Nurs. 2007; 25:2-5.

[14] Higdon ML, Higdon JA. Treatment of oncologic emergencies. Am Fam Physician. 2006; 74:187380.

[15] Krayem HK, Bowles A, Hanbali A. Mediastinal hematoma with SVC syndrome from a central venous catheter insertion: A case report. Chest. 2003; 124:314S. (Abst).

[16] Rowell NP, Gleeson FV. Steroids, radiotherapy, chemotherapy and stents for superior vena caval obstruction in carcinoma of the bronchus. Cochrane Database Syst Rev 2001, Issue 4. Art No: CD001316. DOI: 10.1002/14651858.CD001316.

[17] Bruera E, Ripamonti C. Dyspnea in patients with advanced cancer. In: Berger A, Portenoy R, Weissman D, editors. Principles and practice of supportive oncology. Philadelphia: LippincottRaven; 1998. 295-308.

[18] Pereira J, Mancini I, Bruera E. The management of bleeding in patients with advanced cancer. In: Portenoy RK, Bruera E,eds. Topics in Palliative Care, Volume 4. New York: Oxford University Press, 2000:163-183.

[19] Ahmedzai S. Palliation of respiratory symptoms. In: Doyle D, Hanks GWC, MacDonald N, editors. Oxford textbook of palliative medicine. 2nd edition. New York: Oxford University Press; 1998. p. 584616.

[20] Rousseau P. Nonpain symptom management in terminal care. Clin Geriatr Med 1996; 12 :313-27.

[21] Storey P, Knight C. Dyspnea. In: Management of selected non-pain symptoms in the terminally ill: UNIPAC four. 2nd edition. New York: Mary Ann Liebert; 2003. p. 29-35. 
[22] Chandler S. Nebulized opioids to treat dyspnea. Am J Hosp Palliat Care 1999; 16:418-22.

[23] Shimoyama N, Shimoyama M. Nebulized furosemide as a novel treatment for dyspnea in terminal cancer patients. J Pain Symptom Manage 2002; 23:73-6.

[24] Jacobs L. Managing respiratory symptoms at the end of life. Clin Geriatr Med 2003; 19:225-39.

[25] Coyne P, Viswanathan R, Smith T. Nebulized fentanyl citrate improves patients' perception of breathing, respiratory rate, and oxygen saturation in dyspnea. J Pain Symptom Manage 2002; 23:157-60.

[26] Sarhill N, Walsh D, Nelson K, Hamsi J, LeGrand S, Davis M. Methylphenidate for fatigue in advanced cancer: a prospective open-label pilot study. Am J Hosp Palliat Care 2001; 18:187-92.

[27] Grewal J, Grewal HK, Forman AD. Seizures and epilepsy in cancer: etiologies, evaluation, and management. Curr Oncol Rep 2008; 10(1):63-71.
[28] Singh G, Rees JH, Sander JW. Seizures and epilepsy in oncological practice: causes, course, mechanisms and treatment. J Neurol Neurosurg Psychiatry 2007; 78(4):342-9.

[29] Gagnon B, Mancini I, Pereira J. Palliative management of bleeding events in advanced cancer patients. J Palliat Care 1998; 14:50-54.

[30] Hoskin P, Makin W. The role of surgical and radiological intervention in palliation. In: Oncology for Palliative Medicine. Oxford, UK: Oxford University Press, 1998:229-234.

[31] Breitbart W, Gibson C, Tremblay A. The delirium experience: delirium recall and delirium-related distress in hospitalized patients with cancer, their spouses/ caregivers, and their nurses. Psychosomatics 2002; 43: 183 /94. 